ARTICLE

\title{
Savoring the moment: A link between affectivity and depression
}

\author{
Ian J. Kahrilas · Jennifer L. Smith • Rebecca L. Silton · Fred B. Bryant
}

\begin{abstract}
:
Objective: Positive affectivity (PA; disposition to experience positive moods) and negative affectivity (NA; disposition to experience negative moods) may be risk factors for depression. Low PA may impair positive emotion regulation (savoring), potentially exacerbating depression. Understanding the mechanisms in which temporal domains of savoring influence the relationship between affectivity and depression may help advance depression treatments.

Method: 1,618 participants (1,243 females; 70.0\% Caucasian, 19.1\% Asian, 4.5\% African American, $0.9 \%$ Pacific Islander, $0.7 \%$ American Indian or Alaskan Native, $4.9 \%$ Biracial) ages $17-40$ (M = $18.99, \mathrm{SD}=1.33$ ) completed questionnaires. An exploratory path analysis was run with PA and NA as exogenous variables, savoring domains as mediators, and depression the outcome.

Results: PA and NA were associated with depression and all three savoring temporal domains. Momentary savoring distinctly mediated the relationship between both PA and NA and depression.

Limitations: The data are self-report and cross-sectional, precluding causal inference. Post-hoc power analysis indicated that the present study was underpowered. The use of a college sample primarily comprised of Caucasian women limits generalizability.

Conclusions: Affectivity was associated with the temporal domains of savoring and indirectly associated with depression via momentary savoring. All temporal domains of savoring may bolster PA and mitigate NA. Momentary savoring may reduce depression symptoms in individuals with low PA and high NA.
\end{abstract}

Keywords: positive affectivity, negative affectivity, savoring, positive emotion regulation, depression

\section{Introduction}

Affective theories of mood and anxiety disorders have posited that low positive affectivity is a specific risk factor for depression (Clark \& Watson, 1991; Lewinsohn \& Graf, 1973; Watson, Clark, et al., 1995; Watson, Weber, et al., 1995), whereas high negative affectivity may be a more general indicator of distress that is observed across depression and anxiety disorders, as well as other psychopathology types (Watson \& Clark, 1984). Positive affectivity reflects a tendency to experience intense and frequent episodes of pleasant moods (Watson, 2009), while negative affectivity refers to a tendency to experience negative moods (Watson \& Clark, 1984).

Positive and negative affectivity are theorized to represent stable individual differences indicative of an individual's disposition to experience positive and negative affect (i.e., transient emotional experiences) respectively. To this extent, positive affectivity and negative affectivity are closely associated with highly stable personality traits such as extraversion and neuroticism, 
correspondingly (Costa \& McCrae, 1980; Warr et al., 1983). While certain major life events (e.g., unemployment, disability) are associated with long-term changes in subjective well-being, others (e.g., marriage, widowhood, divorce) only have short-term effects with a tendency to revert back to baseline levels of positive affectivity following these major events (Lucas, 2007; Suh et al., 1996; Watson, 2009). With regard to depression, the frequency of positive life events is not fully explanatory of depression symptoms (Needles \& Abramson, 1990). Rather, the relationship between positive events and depression symptomatology is likely modulated by individual differences ranging from cognitive style (Needles \& Abramson, 1990) to neurobiological factors (Watson, 2009) that influence the interpretation and/or experience of positive events. Related, research has indicated that emotional inertia (i.e., degree to which one's affective state is predicted by a previous affective state) may be a risk factor for future development of mood disorders (Koval et al., 2012; Kuppens et al., 2010). Research has also concurrently indicated that affective instability is related to depression symptoms (e.g., Thompson et al., 2012). Seeking to reconcile these findings, research utilizing experience sampling and controlled laboratory methods found that more resistant negative emotion, specifically, was related to depression while positive emotion continues to fluctuate (Koval et al., 2013). While research has explored the role of negative emotion regulation strategies (e.g., reappraisal, acceptance, problem solving; Aldao et al., 2010) in the context of depression, the same cannot be said about positive emotion regulation (Silton et al., 2020). Characterizing specific positive emotion regulation strategies that mediate the relationship between affectivity and depression could inform treatment and intervention approaches to depression.

\section{Emotion Regulation and Depression}

The connection between negative emotion regulation and depression is well established (Gross, 1998; Gross \& Muñoz, 1995; Joormann \& Gotlib, 2010; Joormann \& Vanderlind, 2014; NolenHoeksema et al., 1993). Individuals with depression are more likely to engage in maladaptive regulation strategies such as rumination, expressive suppression, and catastrophizing and less likely to utilize adaptive strategies like reappraisal and self-disclosure compared to individuals without depression (Garnefski \& Kraaij, 2007; Gross \& John, 2003; Joormann \& Gotlib, 2010). More recently, research has begun to examine the influence of positive emotion regulation on depression symptoms (Feldman et al., 2008; Nelis et al., 2015; Raes et al., 2012; Werner-Seidler et al., 2013). Beck (1979) theorized that dampening positive emotions intensifies and perpetuates depression. Accordingly, greater dampening of positive affect is prospectively associated with increased depression symptoms three and five months later (Raes et al., 2012). Other research has shown that those with depression tend to be apprehensive about experiencing positive affect and thus engage in maladaptive emotion regulation strategies, such as dampening positive affect (Werner-Seidler et al., 2013). Furthermore, Werner-Seidler et al. (2013) showed that depression symptoms are inversely related to strategies implemented to amplify positive affect and depression. In sum, although research is beginning to establish that those with depression tend to engage in maladaptive positive emotion regulation strategies that reduce positive emotion (Carl et al., 2013; Garnefski \& Kraaij, 2007; Gross \& John, 2003; Silton et al., 2020), there has been less focus on identifying strategies that may successfully enhance positive emotion in individuals who are at risk for depression. As such, the present study evaluates the hypothesis that savoring may ameliorate depression symptoms.

\section{Savoring Responses and Savoring Beliefs}

Savoring refers to an awareness of positive experiences and the use of positive emotion 
regulation strategies to enhance and extend positive feelings that are derived from those experiences (Bryant, 1989, 2003; Bryant, Chadwick, \& Kluwe, 2011; Bryant \& Veroff, 2007; Smith \& Bryant, 2017). People initiate savoring responses in reaction to a positive event or affect as a way to maintain, intensify, or prolong positive experience (Bryant \& Veroff, 2007). The original conceptual formulation of savoring (Bryant \& Veroff, 2007) is predicated on the theory that people typically engage in savoring responses in reaction to positive events or affect, which people regulate through cognitive or behavioral strategies. Chronically low levels of positive affectivity would be expected to reduce savoring responses, which over time would lower selfevaluations of savoring ability. While savoring, one may anticipate the enjoyments of future positive experiences, focus on ongoing positive experiences as they occur, or reminisce about past positive experiences. Regardless of the temporal focus, savoring processes regulate positive emotions in the present moment.

In contrast to savoring responses, savoring beliefs are self-perceptions of one's capacity to savor (Bryant, 2003). Although related to ways in which people regulate positive feelings in response to positive events, savoring beliefs are dispositional tendencies that are distinct from specific savoring strategies in which people engage. Stronger savoring beliefs are associated with lower levels of depression symptoms (Bryant, 2003; Eisner et al., 2009; Hou et al., 2016; Ramsey \& Gentzler, 2014; Smith \& Hollinger-Smith, 2015). Examining the correlations between savoring beliefs and depression in two separate samples, Bryant (2003) found a significant negative correlation between savoring the moment and depression in both samples, a significant negative correlation between positive reminiscence and depression in one of the samples, and no correlation between positive anticipation and depression in either sample. In another study, savoring the moment, but not anticipation, was also identified as a unique predictor of lifetime depression symptoms (Carver \& Johnson, 2009). These results suggest that the capacity to savor ongoing positive experiences as they occur may have the strongest relationship with level of depression symptoms. Furthermore, those endorsing higher levels of savoring beliefs report similar experiences as those endorsing high levels of positive affectivity-namely, intense and frequent episodes of positive affect (Bryant \& Veroff, 2007; Watson, 2009).

\section{Savoring and Positive Affect}

Savoring strategies that amplify positive emotions are associated with greater frequency of positive affect (Gentzler et al., 2013; Quoidbach et al., 2010; Smith et al., 2014). As an example, college students who reminisced for one week using either memorabilia or cognitive imagery reported greater increases in frequency of happy feelings compared to participants in a control condition (Bryant et al., 2005). In addition, a present-focused savoring strategy, mindfully photographing beautiful or meaningful subjects, led to more positive moods compared to photographing neutral subjects (Kurtz, 2015). Research has also found that greater savoring beliefs are associated with higher intensity of positive affect and less negative affect (Bryant, 2003; Smith \& Hollinger-Smith, 2013). Across two separate samples, people who reported stronger savoring beliefs also tended to report higher levels of personality traits associated with increased positive affect, such as intensity of happy feelings, self-esteem, frequent happy feelings, and less frequent unhappy feelings (Bryant, 2003). Using experience sampling methodology, Jose, Lim, and Bryant (2012) found that momentary savoring mediated the relationship between daily positive events and momentary happiness, and this effect was stronger for people with higher trait levels of amplifying (i.e., broad types of savoring strategies) and weaker for people with higher trait levels of dampening. Research has also shown that a combination of low capacity to savor the moment and experiencing less positive events is most strongly associated with lower 
positive affect and less life satisfaction (Hurley \& Kwon, 2013; Jose et al., 2012). Collectively, these studies illustrate that higher savoring capacity results in greater frequency and intensity of positive affect, which is representative of elevated positive affectivity. However, while this research has investigated the relationship between savoring beliefs and trait-like attributes such as intensity and frequency of affect and increased self-esteem, previous research has not explicitly examined the relationship between trait affectivity and savoring beliefs within the context of depression. The present study evaluates savoring as a positive emotion regulation strategy that may modify low positive affectivity and thus reduce depression symptoms.

\section{The Focus of the Present Study}

A variety of interventions have been developed that focus on each of the three temporal domains of savoring (i.e., reminiscing, savoring the moment, and anticipating) in an effort to boost happiness (Smith et al., 2014). For example, cultivating the ability to imagine future positive events can enhance anticipating (Quoidbach et al., 2009), taking mindful photographs aids in momentary savoring (Kurtz, 2015), and increasing awareness of recent positive events serves to bolster reminiscing (Seligman et al., 2005). Thus, if savoring mediates the relationship between affectivity and depression, it may be an effective and modifiable target for bolstering positive affectivity and reducing depression symptoms.

Common treatments for depression, including cognitive behavioral therapy (CBT) and antidepressant medication (Price \& Drevets, 2010), leave considerable room for improvement that may be fulfilled by focusing on enhancing PA. These treatments predominantly focus on ameliorating distorted thought patterns and neurotransmitter systems pertaining to negative emotions (Argyropoulos \& Nutt, 2013; Beck, 1979). Approximately 45-65\% of those with depression undergoing CBT do not achieve remission (DeRubeis et al., 2005; Dimidjian et al., 2006). The importance of enhancing PA is corroborated by the fact that patient definitions of depression recovery equally emphasize repair of PA and NA (Demyttenaere et al., 2015). Further, Dunn and colleagues (2019) conducted two separate studies investigating the efficacy of therapeutic and pharmacological approaches to treating depression and mitigating high NA and PA. Results indicated that NA and PA were both uniquely related to depression and that current treatments (CBT, selective serotonin reuptake inhibitors, selective norepinephrine reuptake inhibitors, tricyclic antidepressants, and monoamine oxidase inhibitors) improve NA, but do little to bolster PA (Dunn et al., 2019). This is despite the fact that reductions in PA were more marked than elevated NA in the samples tested, indicating that PA may be a more pressing intervention target (Dunn et al., 2019). Novel treatments have theorized that increased use of dampening appraisals may be a psychological mechanism of reduced PA (Dunn et al., 2018). This implicates positive emotion regulation and savoring, which is underscored by literature illustrating that greater savoring beliefs are correlated with lower levels of depressive symptoms (Bryant, 2003; Eisner et al., 2009; Hou et al., 2016; Ramsey \& Gentzler, 2014; Smith \& HollingerSmith, 2015). A more thorough understanding of the mechanisms of PA and savoring may pave the way for improving depression treatments.

The present study characterizes the relationship between affectivity, savoring beliefs, and depression symptomatology. We evaluated the following hypotheses: 1) replicating past research, positive affectivity will be negatively associated with depression symptoms and negative affectivity will be positively associated with depression symptoms, 2) positive affectivity will be positively associated with all three temporal domains of savoring and negative affectivity will be negatively associated with all three temporal domains of savoring, 3) savoring the moment will be distinctly associated with depression, and 4) savoring the moment will 
distinctly mediate the relationship between affectivity and depression. Despite the present study's focus on PA, mitigating NA remains an important factor to address in depression with research demonstrating that both are independently related to depression symptoms (Dunn et al., 2019). Additionally, given the negative associations that exist between stable negative traits and savoring (e.g., neuroticism; Bryant, 2003), NA was included as an exogenous variable in the exploratory path analysis. Further, including NA facilitates the analysis of PA and NA's unique relationship with depression via the temporal domains of savoring by statistically controlling for the effects of the other. Because anxiety and depression symptoms frequently co-occur (American Psychiatric Association, 2013; Clark, 1989; Mineka et al., 1998), we accounted for the effects of anxiety by including measures of anxious arousal (somatic) and anxious apprehension (worry) symptoms (Sharp et al., 2015) in our analyses. Additionally, research suggests that worry spans temporal domains and is associated with rumination about past events and hopelessness regarding the future (Andrews \& Borkovec, 1988; MacLeod \& Byrne, 1996) as well as procrastination (Stöber \& Joormann, 2001), each of which may overlap with the temporal domains of savoring. Further, since research indicates that females tend to report greater savoring capacity than do males (Bryant \& Veroff, 2007), gender was included as a covariate.

The present study utilized a parallel mediation model with cross-sectional data. Some researchers have advocated against this practice since correlational data do not afford causal interpretation (Maxwell et al., 2011). Alternatively, Hayes (2018) advocated for a more relaxed stance: "We should not let the limitations of our data collection efforts constrain the tools we bring to the task of trying to understand what our data might be telling us about the processes we are studying" (p. 18). Many researchers share this sentiment as indicated by their use of mediation analyses with cross-sectional data (Blashill et al., 2010; Gaunt \& Scott, 2014; Goodin et al., 2009; Kung et al., 2016; Lee et al., 2014; Li et al., 2011; Osborne et al., 2015; Pollack et al., 2012; Rees \& Freeman, 2009; Smith et al., 2016; Thai et al., 2016; Thomas \& Bowker, 2015; Torres \& Taknint, 2015; Webb et al., 2016). Thus, the present study utilized cross-sectional mediation analyses while recognizing its preclusion of causal inference.

\section{Method}

\section{Participants}

Participants $(N=2,482)$ were recruited from introductory psychology courses. Participants received course credit for completion of an online survey. Case wise deletion was used to omit participants $(n=864)$ that had missing responses to any questionnaires used in the present study. The final sample of 1,618 participants ( $n=375$ males, $n=1,243$ females) ranged in age from 17 $40(M=18.99$ years, $S D=1.33)$ and was $70.0 \%$ Caucasian, $19.1 \%$ Asian, $4.5 \%$ Black or African American, $0.9 \%$ Native Hawaiian or other Pacific Islander, $0.7 \%$ American Indian or Alaskan Native, and $4.9 \%$ Biracial; $11.4 \%$ reported that they were Hispanic/Latinx and $88.6 \%$ were not Hispanic/Latinx. The study was approved by the University's Institutional Review Board, and informed consent was provided to all participants prior to beginning the survey.

\section{Questionnaire Measures}

Savoring capacity. We administered the Savoring Beliefs Inventory (Bryant, 2003) to assess participants' savoring capacity. The SBI measures the perception of one's ability to feel pleasure through anticipating positive experiences, savoring positive moments as they occur, and reminiscing about past positive events (Bryant \& Veroff, 2007). The SBI was analyzed as three eight-item subscales pertaining to temporal forms of savoring: anticipating (e.g., "Before a good thing happens, I look forward to it in ways that give me pleasure in the present."), savoring the 
moment (e.g., "I know how to make the most of a good time."), and reminiscing (e.g., "I enjoy looking back on happy times from my past."). Items are rated on a seven-point Likert scale from "1" (strongly disagree) to "7" (strongly agree). The three temporal subscales of the SBI were originally conceived as separate, intercorrelated measures of individuals' characteristic capacities to savor. Test-retest reliability assessments provide cross-cultural evidence for the stability of the SBI subscales (Bryant, 2003; Kawakubo et al., 2019). Prospective research testing predictive validity found that participants' SBI scores predicted ability to anticipate, momentarily savor, or reminisce upon winter break three months later (Bryant, 2003). This empirical evidence collectively supports the conclusion that the three SBI subscales reflect stable traits that manifest themselves in predictable forms of behavioral and emotion experience over time. Bryant (2003) found moderate to high internal consistency across all three subscales. The present study replicated these findings (Anticipating, $\omega=.87$; Savoring the Moment, $\omega=.85$; and Reminiscing, $\omega=.86$ ).

Depression severity. To evaluate depression severity, the nine-item Patient Health Questionnaire (PHQ-9; Kroenke et al., 2001) was administered. PHQ-9 items are scored from "0" (not at all) to "3" (nearly every day) and are based on the depression criteria from the Diagnostic and Statistical Manual of Mental Disorders, Fourth Edition. Internal consistency of the PHQ-9 in the present study $(\omega=.87)$ was consistent with past research (Kroenke et al., 2001).

Affectivity and anxiety symptoms. To assess for positive and negative affectivity as well as anxiety, the 39-item Mood and Anxiety Symptoms Questionnaire (Watson, Clark, et al., 1995; Watson, Weber, et al., 1995) was administered. The MASQ was analyzed as three separate subscales: the eight-item negative affectivity (NA) Scale (MASQ-NA8; e.g., "Felt withdrawn from other people"), the 14-item positive affectivity (PA) Scale (MASQ-PA14; e.g., "Felt cheerful"), and the 17-item Anxious Arousal Scale (MASQ-AA; e.g., "Startled easily"). Previous literature has supported these oblique factors in two independent samples of individuals at-risk for depression and anxiety (Kendall et al., 2015; Nitschke et al., 2001). Participants rated their affectivity and anxiety symptoms using a five-point Likert scale from " 1 " (not at all) to " 5 " (extremely). Consistent with previous research (Bredemeier et al., 2010), the MASQ scales demonstrated good to excellent internal consistency(MASQ-NA8, $\omega=.80$; MASQ-PA14, $\omega=.94$; and MASQ-AA, $\omega=.88$ ).

Worry. The 16-item Penn State Worry Questionnaire (Meyer et al., 1990) was used to assess for the trait of worrying. PSWQ items are rated on a five-point Likert scale from "1" (not at all typical) to "5" (very typical). Meyer and colleagues (1990) found a high degree of internal consistency in the PSWQ, and the present study found good consistency $(\omega=.87)$.

\section{Results}

\section{Depression Severity}

To provide clinically relevant descriptive information regarding depression severity in the sample, participants were categorized into five depression severity groups based on established PHQ-9 cutoff scores: minimal (1-4), mild (5-9), moderate (10-14), moderately severe (15-19), and severe (20-27; Kroenke et al., 2001). Group means, standard deviations, and reliability coefficients of primary variables of interest (PA, NA, and savoring the moment) were calculated for each of the depression severity groups (see Table 1). Pairwise t-test comparisons with Holm correction were conducted to assess mean differences between each depression group for PA, NA, and savoring the moment. Analyses indicated significant differences between all groups for all variables except for the difference in mean PA between moderately severe and severe depression groups. 
Table 1

Descriptive Statistics Among Positive and Negative Affectivity and Savoring the Moment for each Depression Severity Group

\begin{tabular}{|c|c|c|c|c|c|c|c|c|c|c|c|}
\hline \multirow[b]{2}{*}{ Depression Group } & \multirow[b]{2}{*}{$\mathrm{n}$} & \multirow[b]{2}{*}{$\%$} & \multicolumn{3}{|c|}{ Positive Affectivity } & \multicolumn{3}{|c|}{ Negative Affectivity } & \multicolumn{3}{|c|}{ Savoring the Moment } \\
\hline & & & Mean & $S D$ & $\omega$ & Mean & $S D$ & $\omega$ & Mean & $S D$ & $\omega$ \\
\hline Minimal & 613 & 37.9 & 47.9 & 10.8 & .93 & 14.8 & 4.2 & .70 & 43.9 & 7.8 & .81 \\
\hline Mild & 561 & 34.7 & 43.2 & 10.2 & .92 & 18.4 & 4.5 & .65 & 40.3 & 8.3 & .83 \\
\hline Moderate & 269 & 16.6 & 38.9 & 10.3 & .91 & 23.0 & 4.2 & .50 & 35.9 & 8.0 & .78 \\
\hline Moderately Severe & 125 & 7.7 & 34.5 & 11.3 & .93 & 26.3 & 4.3 & .49 & 31.5 & 8.7 & .82 \\
\hline Severe & 50 & 3.1 & 33.0 & 14.6 & .96 & 29.3 & 4.8 & .55 & 27.9 & 9.4 & .83 \\
\hline
\end{tabular}

Note. Holm corrected pairwise t-tests indicated significant differences between each depression group for all variables except between moderately severe and severe groups for PA. $S D=$ standard deviation, $\omega=$ McDonald's Omega.

\section{Correlations Among Study Variables}

Pearson correlations were computed among the primary study variables (see Table 2). As expected, PA was positively associated with all temporal domains of savoring. NA, depression, and anxious arousal were negatively associated with all temporal savoring domains. All correlations were statistically significant.

Table 2

Correlations among affectivity, temporal domains of savoring, depression severity, and anxious arousal measures $(N=1,618)$.
1.
2.
3.
4.
5.
6.
7. 8.

1. Anticipating

2. Savoring the Moment $\quad .68$

3. Reminiscing $\quad .75 \quad .72$

4. Positive Affectivity $\quad .45 \quad .59 \quad .46$

5. Negative Affectivity $\quad-.36 \quad-.55 \quad-.40 \quad-.40$

6. Anxious Arousal $\quad-.28 \quad-. .31 \quad-.28 \quad-.08 \quad .58$

$\begin{array}{lllllll}\text { 7. Depression } & -.34 & -.51 & -.36 & -.42 & .74 & .54\end{array}$

$\begin{array}{llllllll}\text { 8. Worry } & -.12 & -.32 & -.16 & -.20 & .46 & .35 & .46\end{array}$

Positive Affectivity, Negative Affectivity, and Anxious Arousal as Predictors of Depression The tripartite model posits that depression and anxiety have specific relations with three affective dimensions: PA, NA, and anxious arousal (Watson, Clark, et al., 1995; Watson, Weber, et al., 1995). Given the present study's focus on PA and depression, we wanted to confirm the unique relation between each of these dimensions and depression symptoms in the present sample. Per the tripartite model, we anticipated that low levels of PA and high levels of NA would be 
positively associated with depression symptoms, and that anxious arousal would be unrelated to depression symptoms. Multiple regression analyses were conducted with PA, NA, and anxious arousal as predictors and depressions with no covariates. Diverging from the specific association between PA and depression proposed by Clark and Watson (1991, 1995), results from the test sample indicated that each of the predictors were uniquely associated with depression. NA $[b=.52, \beta=.55, t(1614)=25.47, p<.001]$ was the strongest predictor of depression, followed by anxious arousal $[b=.11, \beta=.21, t(1614)=10.38, p<.001]$, and lastly PA $[b=-.09, \beta=-.19, t(1614)$ $=-10.55, p<.001]$.

\section{Mediation Analyses}

Path analyses were run in R (R Core Team, 2019) using the lavaan package (Rosseel, 2012) to assess the indirect effects of PA and NA on depression via three temporal domains of savoring capacity while accounting for the variance associated with gender, worry, and anxious arousal (see Figure 1). Exogenous variables (PA and NA) were allowed to correlate with one another, as were the residual variances of each of the temporal domains of savoring. Maximum likelihood estimation was used to estimate path coefficients, and bias-corrected bootstrap confidence intervals based on 10,000 bootstrap samples were used to estimate indirect effects of temporal domains of savoring between affectivity and depression. The fully saturated model contained 45 free parameters with zero degrees of freedom, resulting in perfect goodness of fit indices. Results (see Figure 1 and Table 3) showed that PA was associated with anticipating (standardized: $a_{1}=$ .41, unstandardized: $a_{1}=.30, p<.001$ ), savoring the moment (standardized: $a_{2}=.46$, unstandardized: $a_{2}=.36, p<.001$ ), and reminiscing (standardized: $a_{3}=.39$, unstandardized: $a_{3}=$ $.28, p<.001)$. There were significant associations between NA and anticipating (standardized: $a_{\mathrm{i}}$ $=-.11$, unstandardized: $a_{\mathrm{i}}=-.16, p<.001$ ), savoring the moment (standardized: $a_{\mathrm{ii}}=-.29$, unstandardized: $a_{\mathrm{ii}}=-.44, p<.001$ ), and reminiscing (standardized: $a_{\mathrm{iii}}=-.16$, unstandardized: $a_{\mathrm{iii}}=$ -.23, $p<.001)$. Further, savoring the moment was related to lower depression severity (standardized: $b_{2}=-.07$, unstandardized: $b_{2}=-.04, p=.024$ ), while anticipating and reminiscing were not. Bias-corrected bootstrap confidence intervals (based on 10,000 bootstrap samples; see Table 3) for the indirect effects of temporal domains of savoring between PA and depression did not include zero for savoring the moment (95\% CI [-.028, -.002], $\left.a_{2} b_{2}=-.01\right)$ but did include zero for anticipating $\left(95 \% \mathrm{CI}[-.009, .012], a_{1} b_{1}=.00\right)$ and reminiscing $\left(95 \%\right.$ CI $\left.[-.009, .013], a_{3} b_{3}=.00\right)$. Similarly, bias-corrected bootstrap confidence intervals for the indirect effects of temporal domains of savoring between NA and depression did not include zero for savoring the moment $\left(95 \% \mathrm{CI}[.003, .035], a_{\mathrm{ii}} b_{2}=.02\right)$ but did include zero for anticipating $\left(95 \% \mathrm{CI}[-.007, .005], a_{\mathrm{i}} b_{1}=.00\right)$ and reminiscing $\left(95 \%\right.$ CI $\left.[-.011, .007], a_{\mathrm{iii}} b_{3}=.00\right)$. Notably, there is a negative indirect effect between PA and depression via savoring the moment with a positive relationship between PA and savoring the moment. This signifies that the positive association between PA and momentary savoring results in reduced depression scores that accounts for a portion of the significant negative relationship between PA and depression (standardized: $c^{\prime}{ }^{P A}=-.16$, unstandardized: $\left.c^{\prime} \mathrm{PA}=-.08, p<.001\right)$. The direct effect of NA on depression was also significant (standardized: $c^{\prime} \mathrm{NA}=.49$, unstandardized: $c^{\prime} \mathrm{NA}=.02, p<.001$ ). 


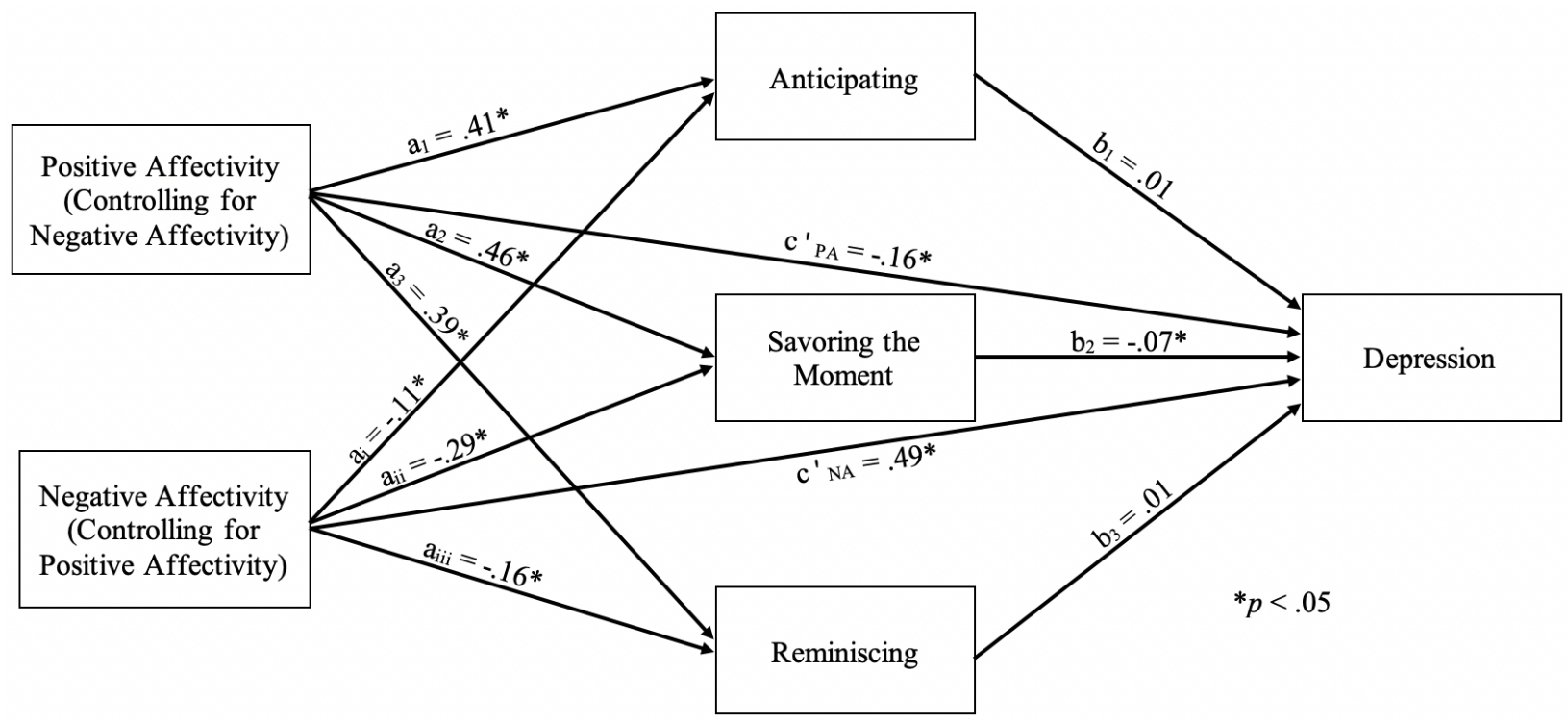

Figure 1. Standardized structural diagram of path model with three mediators: anticipating, savoring the moment, and reminiscing $(N=1,618)$. The diagram shows $\mathrm{A})$ the effect of positive and negative affectivity on depression severity and B) the direct and indirect pathways associating affectivity with temporal domains of savoring and depression. Sex, worry, and anxious arousal were included as covariates in the model, but were omitted from the figure to streamline presentation. Positive and negative affectivity were allowed to correlate with each other and with the three covariates, which were also allowed to intercorrelate. These intercorrelations were omitted from the path diagram to streamline presentation. The residual variances in the mediators and in depression were also estimated parameters in the structural model. These residual variances were also omitted from the path diagram to streamline presentation.

Table 3

Unstandardized path coefficients from the structural equation model using positive and negative affectivity to predict depression with savoring subscales as mediators $(N=1,618)$. The structural model included three covariates (sex, worry, and anxious arousal) as exogenous independent variables, each of which had direct effects on the three mediators and depression.

\begin{tabular}{|c|c|c|c|c|c|c|c|c|c|c|c|c|c|c|c|c|c|c|c|c|}
\hline \multirow[b]{3}{*}{ Antecedent } & \multirow{2}{*}{\multicolumn{4}{|c|}{$M_{1}(\mathrm{ANT})$}} & \multirow{2}{*}{\multicolumn{4}{|c|}{$M_{2}(\mathrm{MOM})$}} & \multirow{2}{*}{\multicolumn{4}{|c|}{$M_{3}(\mathrm{REM})$}} & \multirow{2}{*}{\multicolumn{4}{|c|}{$Y(\mathrm{DEP})$}} & \multicolumn{4}{|c|}{ Indirect Effects } \\
\hline & & & & & & & & & & & & & & & & & \multirow{2}{*}{\multicolumn{2}{|c|}{ Coef. }} & \multicolumn{2}{|c|}{$95 \% \mathrm{bcCI}$} \\
\hline & & Coef. & $S E$ & $p$ & & Coef. & $S E$ & $p$ & & Coef. & $S E$ & $p$ & & Coef. & $S E$ & $p$ & & & Lower & Upper \\
\hline \multirow{4}{*}{\multicolumn{2}{|c|}{$\begin{array}{c}\mathrm{PA} \\
M_{1}(\mathrm{ANT}) \\
M_{2}(\mathrm{MOM}) \\
M_{3}(\mathrm{REM})\end{array}$}} & 0.30 & 0.02 & $<.001$ & $a_{2}$ & 0.36 & 0.02 & $<.001$ & $a_{3}$ & 0.28 & 0.02 & $<.001$ & $c_{P A}^{\prime}$ & -0.08 & 0.01 & $<.001$ & & & & \\
\hline & & & & & & & & & & & & & $\hat{b}_{1}$ & 0.00 & 0.02 & 0.796 & $a_{1} b_{1}$ & 0.00 & -0.009 & 0.012 \\
\hline & & & & 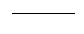 & & & 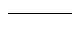 & {[} & & - & 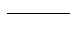 & 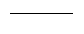 & $b_{2}$ & -0.04 & 0.02 & 0.024 & $a_{2} b_{2}$ & -0.01 & -0.028 & -0.002 \\
\hline & & & & & & & & & & & & & $b_{3}$ & 0.01 & 0.02 & 0.697 & $a_{3} b_{3}$ & 0.00 & -0.009 & 0.013 \\
\hline \multirow{3}{*}{$\begin{array}{l}\mathrm{NA} \\
\qquad M_{1}(\mathrm{ANT}) \\
M_{2}(\mathrm{MOM}) \\
M_{3}(\mathrm{REM})\end{array}$} & $a_{i}$ & -0.16 & 0.05 & $<.001$ & $a_{i i}$ & -0.44 & 0.04 & $<.001$ & $a_{i i i}$ & -0.23 & 0.05 & $<.001$ & $c_{N A}^{\prime}$ & 0.46 & 0.02 & $<.001$ & & & & \\
\hline & & & & & & & & & & & & & $\begin{array}{l}o_{1} \\
b_{2}\end{array}$ & $\begin{array}{r}0.00 \\
-0.04\end{array}$ & $\begin{array}{l}0.02 \\
0.02\end{array}$ & $\begin{array}{l}0.796 \\
0.024\end{array}$ & $\begin{array}{l}a_{i} b_{1} \\
a_{i j} b_{2}\end{array}$ & $\begin{array}{l}0.00 \\
0.02\end{array}$ & $\begin{array}{r}-0.007 \\
0.003\end{array}$ & $\begin{array}{l}0.005 \\
0.035\end{array}$ \\
\hline & & 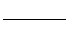 & 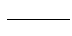 & - & & 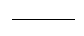 & 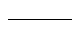 & - & & 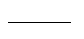 & 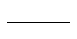 & - & $b_{3}$ & 0.01 & 0.02 & 0.697 & $a_{i i i} b_{3}$ & 0.00 & -0.011 & 0.007 \\
\hline \multicolumn{21}{|l|}{ Covariates: } \\
\hline SEX & & 2.89 & 0.41 & $<.001$ & & 1.63 & 0.37 & $<.001$ & & 2.61 & 0.40 & $<.001$ & & 0.53 & 0.21 & 0.012 & & & & \\
\hline WOR & & 0.06 & 0.02 & $<.006$ & & -0.07 & 0.02 & $<.001$ & & 0.04 & 0.02 & $<.088$ & & 0.07 & 0.01 & $<.001$ & & - & & \\
\hline ANX & & -0.18 & 0.02 & $<.001$ & & -0.08 & 0.02 & $<.001$ & & -0.14 & 0.02 & $<.001$ & & 0.10 & 0.01 & $<.001$ & & - & - & \\
\hline$R^{2}$ & & & 0.29 & & & & 0.48 & & & & 0.30 & & & & 0.61 & & & & & \\
\hline$F$ & & & 132.29 & & & & 296.23 & & & & 138.36 & & & & 315.26 & & & & & \\
\hline$p$ & & & $<.001$ & & & & $<.001$ & & & & $<.001$ & & & & $<.001$ & & & & & \\
\hline
\end{tabular}

Note. $S E=$ Standard Error, $\mathrm{PA}=$ Positive Affectivity, NA = Negative Affectivity, ANT = Anticipating, $\mathrm{MOM}=$ Savoring the Moment, REM = Reminiscing, DEP = Depression, $\mathrm{WOR}=$ Worry, ANX = Anxious Arousal. The symbols appearing to the left of the direct effects (e.g., $a_{1}$ ) 
refer to the labeled paths in Figure 2. The symbols to the left of each indirect effect coefficient represent the products of each of the constituent direct effects that compose each indirect effect. For example, symbol $a_{1} b_{1}$ represents the product of the direct effect of PA on ANT (i.e., $a_{1}$ ) and the direct effect of ANT on DEP (i.e., $\left.b_{1}\right)$, or $\left(a_{1}\right)\left(b_{1}\right)$.

\section{Discussion}

The present study examined the relationship between affectivity (PA and NA) and depression symptoms via the future-, present-, and past-focused temporal domains of savoring beliefs (i.e., self-reported capacity to savor by anticipating, savor the moment, and savor by reminiscing, respectively). As predicted, results showed that PA and NA were associated with all three temporal domains of savoring. Savoring the moment distinctly mediated the relationship between affectivity and depression; whereas, the other temporal domains did not mediate this relationship. Replicating past research, we also found a relationship between affectivity and depression symptoms (Chorpita, 2002; Clark \& Watson, 1991; Dunn et al., 2019; Khazanov \& Ruscio, 2016; Watson, Clark, et al., 1995; Watson, Clark, \& Carey, 1988; Watson, Weber, et al., 1995). Of note, we found that the effect size for the bivariate relationship between NA and depression (i.e., 55\% shared variance) was roughly three times larger than the effect size for the relationship between PA and depression (i.e., 18\% shared variance); but given that NA is theorized to be a common factor shared among depression and anxiety (Watson, Clark, et al., 1995; Watson, Weber, et al., 1995), higher NA may also be increased due to co-occurring anxiety symptoms. These findings are similar to results from a meta-analysis suggesting that low positive emotionality creates an inherent vulnerability to depression, but perhaps to a lesser degree than previously surmised (Khazanov \& Ruscio, 2016).

While findings from the present study imply that structured interventions aimed at enhancing any of the three temporal domains of savoring may serve to attenuate levels of NA and bolster levels of PA and well-being, only savoring the moment is likely to reduce depression symptoms. This latter finding is consistent with previous research showing that momentary savoring capacity has a stronger negative association with depressive symptoms than do reminiscing and anticipating (Bryant, 2003; Carver \& Johnson, 2009). Together, these findings indicate that developing interventions to promote savoring the moment may be effective in reducing depression.

When partitioned by pre-established depression severity cutoff-scores (Kroenke et al., 2001), the majority of the sample fell into minimal and mild depression groups, with significantly fewer participants in the moderate to severe groups. This result is consistent with a previous study conducted by Kroenke and colleagues (2001) that categorized a sample of 580 adult participants into groups based on PHQ-9 depression cut-off scores. It is also critical to note that 444 participants $(27.4 \%)$ of the total present sample likely meet clinical criteria for a depression diagnosis as indicated by scoring 10 or higher on the PHQ-9 (Kroenke et al., 2001). Additionally, pairwise comparisons indicate that as participants increase in depression severity, levels of PA and capacity to savor the moment decrease while NA increases. This supports a dimensional conceptualization of the relationship between depression symptoms and individual difference factors, the present study indicates that a gradual decrease in PA/savoring the moment and increase in NA accompany a rise in depression severity.

The present study expands on previous research that has investigated the relationship between positive emotion regulation and depression by assessing beliefs about positive emotion regulation, specifically savoring, across past, present, and future temporal domains. As such, these findings suggest that savoring the moment, as opposed to reminiscing or anticipating, may 
be instrumental in bolstering PA and reducing NA to ameliorate depression symptoms. This conclusion is further supported by positive psychological interventions that include training in momentary savoring strategies to reduce depression (Hurley \& Kwon, 2013; McMakin et al., 2011; Smith \& Hanni, 2019). In particular, a savoring-based intervention that instructed female college students with symptoms of dysphoria to make positive self-attributions for recent positive events was effective in reducing depression symptoms and sustaining positive affect following positive events (McMakin et al., 2011). In another study, participants who received training in the use of strategies for savoring the moment, such as memory building and expressing positive emotions, displayed lower depression and lower negative affect after two weeks compared to a control group (Hurley \& Kwon, 2013). While interventions targeting reminiscing and anticipating may serve to increase PA and decrease NA, patients presenting with depression may require more specific treatment focused on savoring the present moment compared to a non-clinical sample. Supporting this notion, increased attention to positive stimuli is likely one mechanism through which savoring influences depression symptoms (Carl et al., 2013). Although it should be noted that savoring and mindfulness are not analogous (Bryant \& Veroff, 2007), the importance of moment-to-moment awareness in treating depression is corroborated by mindfulness-based interventions (Gu et al., 2015).

\section{Limitations}

The present study has several limitations. First, the present results are based solely on self-report measures. Although self-report data are often inordinately criticized (Chan, 2009), such measures are not without problems. Self-report methods are prone to exaggeration or underreporting, both of which may be caused by social desirability bias, or a tendency to present oneself favorably (Fisher, 1993). While the PHQ-9 is frequently used to screen for depression and track treatment outcomes in research studies and clinical settings, the present study did not implement clinical interviews to validate the self-report data. Future research in this area might consider using a clinical interview to confirm depression diagnoses. However, the PHQ-9 allows for a dimensional conceptualization of depression symptoms, which is likely to be more consistent with the range of affective and cognitive experiences that co-vary with depression symptoms (Levin et al., 2007).

Second, the present study is limited by its cross-sectional design, which precludes unequivocal conclusions about cause and effect. To overcome this limitation, future research should aim to extend the present findings using a longitudinal, randomized control trial (RCT) design to evaluate the impact of various savoring interventions designed to specifically target each of the three temporal domains in a sample of participants with low levels of PA and depression. In addition, more research is needed to understand the extent to which mindfulnessbased interventions that focus on developing moment-to-moment awareness also indirectly enhance positive emotion regulation and savoring the moment, or whether interventions specifically designed to enhance savoring of positive events in the moment effectively reduce depression. Additionally, all subscales (anticipating, savoring the moment, reminiscing) measure one's capacity to generate positive feelings in the moment while focusing on either past, present, or future positive experiences (Bryant \& Veroff, 2007). Studies utilizing experience sampling methods (e.g., Koval et al., 2013) offer stronger conclusions regarding temporal fluctuations of emotion and depression symptoms.

The presence of multicollinearity, or tautological logic, can be argued due to the high correlation between NA and depression in the present sample and the fact that depressed mood (NA) forms a central construct of depression. Other researchers analyzing the association 
between affectivity (measured with the MASQ) and depression concluded that tautological logic did not compromise their analyses (Dunn et al., 2019). Additionally, the constructs of NA and depression are theoretically distinct despite being related. NA is conceptualized as a general indicator of distress observed across depression, anxiety, and other psychopathology types (Watson \& Clark, 1984). It is conceptually disparate from positive emotions; one with high NA does not necessarily also lack joy, excitement, or enthusiasm, which are hallmarks of depression (Watson \& Clark, 1984). Nitschke and colleagues (2001) corroborated this conceptualization via factor analysis, illustrating that the MASQ-NA subscale overlaps with anxiety and depression factors. Other research indicates that the MASQ-PA scale is a superior means of screening for depression compared to the MASQ-NA scale, further suggesting that NA is conceptually distinct from depression (Bredemeier et al., 2010). The PHQ-9, on the other hand, was designed to map onto criteria for major depressive disorder diagnosis in the Diagnostic and Statistical Manual of Mental Disorders (Kroenke \& Spitzer, 2002). As such, the PHQ-9 was formulated for use in clinical settings with robust diagnostic sensitivity (Kroenke \& Spitzer, 2002; Kroenke, Spitzer, \& Williams, 2001). Nonetheless, further clarification on the overlap between affectivity and depression are grounds for future research.

Finally, a post-hoc power analysis - using the bmem package (Zhang, 2014), specifying 1,000 Monte Carlo simulations, each with 1,000 bootstrap samples -indicated that the present sample provided less than optimal statistical power. In particular, our present sample $(N=1,618)$ yielded $60.5 \%$ power to detect a significant indirect effect of savoring the moment between PA/NA and depression via bootstrapping. Further analyses indicated that a sample size of 2,700 is required in order to reach $80 \%$ power for these indirect effects. This latter finding underscores the fact that researchers need to recruit large sample sizes to detect significant effects in complex mediation models.

\section{Conclusion}

This is one of the first studies to examine the degree to which the three temporal domains of savoring mediate the relationship between affectivity and depression symptoms. Interventions that focus on bolstering any of the temporal domains of savoring may benefit those with low PA or high NA. However, enhancing momentary savoring may be the critical temporal domain to consider adapting as an intervention to ameliorate depression. Overall, our results suggest that interventions targeting positive emotion regulation may have considerable benefit for clinical and non-clinical populations. In advancing this research, RCT methodology should be implemented to confirm causality and benefit among individuals with depression disorders.

\section{Acknowledgments}

The authors thank the anonymous reviewers whose thoughtful feedback was instrumental in improving the quality of this manuscript.

\section{Authors}

Ian J. Kahrilas

Loyola University Chicago

ikahrilas@luc.edu

Jennifer L. Smith

Mather Institute, USA

Rebecca L. Silton 
Loyola University Chicago

Fred B. Bryant

Loyola University Chicago

\section{Publishing Timeline}

Received 10 October 2018

Accepted 29 March 2020

Published 1 June 2020

\section{References}

Adler, A., \& Seligman, M. E. P. (2016). Using wellbeing for public policy: Theory, measurement, and recommendations. International Journal of Wellbeing, 6(1), 1-35. https://doi.org/10.5502/ijw.v6i1.429

Aiken, L. S., West, S. G., \& Reno, R. R. (1991). Multiple regression: Testing and interpreting interactions. Sage.

Aldao, A., Nolen-Hoeksema, S., \& Schweizer, S. (2010). Emotion-regulation strategies across psychopathology: A meta-analytic review. Clinical Psychology Review, 30(2), 217-237. https://doi.org/10.1016/j.cpr.2009.11.004

American Psychiatric Association. (2013). Diagnostic and statistical manual of mental disorders (5th ed.). https://doi.org/10.1176/appi.books.9780890425596

Andrews, V. H., \& Borkovec, T. D. (1988). The differential effects of inductions of worry, somatic anxiety, and depression on emotional experience. Journal of Behavior Therapy and Experimental Psychiatry, 19(1), 21-26. https://doi.org/10.1016/0005-7916(88)90006-7

Argyropoulos, S. V., \& Nutt, D. J. (2013). Anhedonia revisited: Is there a role for dopamine-targeting drugs for depression? Journal of Psychopharmacology, 27(10), 869-877. https://doi.org/10.1177/0269881113494104

Beck, A. T. (1979). Cognitive therapy and the emotional disorders. Penguin.

Blashill, A. J., \& Vander Wal, J. S. (2010). The role of body image dissatisfaction and depression on HAART adherence in HIV positive men: Tests of mediation models. AIDS and Behavior, 14(2), 280-288. https://doi.org/10.1007/s10461-009-9630-2

Bredemeier, K., Spielberg, J. M., Silton, R. L., Berenbaum, H., Heller, W., \& Miller, G. A. (2010). Screening for depressive disorders using the mood and anxiety symptoms questionnaire anhedonic depression scale: A receiver-operating characteristic analysis. Psychological Assessment, 22(3), 702-710. https://doi.org/10.1037/a0019915

Bryant, F. B. (1989). A four-factor model of perceived control: Avoiding, coping, obtaining, and savoring. Journal of Personality, 57(4), 773-797. http://dx.doi.org/10.1111/j.1467-6494.1989.tb00494.x

Bryant, F. B. (2003). Savoring Beliefs Inventory (SBI): A scale for measuring beliefs about savouring. Journal of Mental Health, 12(2), 175-196. https://doi.org/10.1080/0963823031000103489

Bryant, F. B., Chadwick, E. D., \& Kluwe, K. (2011). Understanding the processes that regulate positive emotional experience: Unsolved problems and future directions for theory and research on savoring. International Journal of Wellbeing, 1(1). https://doi.org/10.5502/ijw.v1i1.18

Bryant, F. B., Smart, C. M., \& King, S. P. (2005). Using the past to enhance the present: Boosting happiness through positive reminiscence. Journal of Happiness Studies, 6(3), 227-260. https://doi.org/10.1007/s10902-005-3889-4

Bryant, F. B., \& Veroff, J. (2007). Savoring: A new model of positive experience. Lawrence Erlbaum Associates Publishers.

Carl, J. R., Soskin, D. P., Kerns, C., \& Barlow, D. H. (2013). Positive emotion regulation in emotional disorders: A theoretical review. Clinical Psychology Review, 33(3), 343-360. https://doi.org/10.1016/j.cpr.2013.01.003

Carver, C. S., \& Johnson, S. L. (2009). Tendencies toward mania and tendencies toward depression have distinct motivational, affective, and cognitive correlates. Cognitive Therapy and Research, 33, 552. https://doi.org/10.1007/s10608-008-9213-y 
Chan, D. (2009). Statistical and methodological myths and urban legends: Doctrine, verity and fable in the organizational and social sciences. Taylor \& Francis.

Chorpita, B. F. (2002). The tripartite model and dimensions of anxiety and depression: An examination of structure in a large school sample. Journal of Abnormal Child Psychology, 30(2), 177-190. https://doi.org/10.1023/A:1014709417132

Clark, Lee A., \& Watson, D. (1991). Tripartite model of anxiety and depression: Psychometric evidence and taxonomic implications. American Psychological Association, 100(3), 316-336. http://dx.doi.org/10.1037/0021-843X.100.3.316

Clark, Lee A. (1989). The anxiety and depressive disorders: Descriptive psychopathology and differential diagnosis. In Personality, psychopathology, and psychotherapy. Anxiety and depression: Distinctive and overlapping features (pp. 83-129). San Diego, CA: Academic Press.

Cohen, J. (1988). Statistical power analysis for the behavioral sciences (2nd ed.). Hilsdale: NJ: Lawrence Earlbaum Associates.

Cohen, J. (1992). A power primer. Psychological Bulletin, 112(1), 155. http://dx.doi.org/10.1037/00332909.112.1.155

Costa, P. T., \& McCrae, R. R. (1980). Influence of extraversion and neuroticism on subjective well-being: Happy and unhappy people. Journal of Personality and Social Psychology, 38(4), 668-678. https://doi.org/10.1037/0022-3514.38.4.668

Demyttenaere, K., Donneau, A.-F., Albert, A., Ansseau, M., Constant, E., \& van Heeringen, K. (2015). What is important in being cured from depression? Discordance between physicians and patients (1). Journal of Affective Disorders, 174, 390-396. https://doi.org/10.1016/j.jad.2014.12.004

DeRubeis, R. J., Hollon, S. D., Amsterdam, J. D., Shelton, R. C., Young, P. R., Salomon, R. M., O'Reardon, J. P., Lovett, M. L., Gladis, M. M., Brown, L. L., \& Gallop, R. (2005). Cognitive therapy vs medications in the treatment of moderate to severe depression. Archives of General Psychiatry, 62(4), 409-416. https://doi.org/10.1001/archpsyc.62.4.409

Dimidjian, S., Hollon, S. D., Dobson, K. S., Schmaling, K. B., Kohlenberg, R. J., Addis, M. E., Gallop, R., McGlinchey, J. B., Markley, D. K., Gollan, J. K., Atkins, D. C., Dunner, D. L., \& Jacobson, N. S. (2006). Randomized trial of behavioral activation, cognitive therapy, and antidepressant medication in the acute treatment of adults with major depression. Journal of Consulting and Clinical Psychology, 74(4), 658-670. https://doi.org/10.1037/0022-006X.74.4.658

Dunn, B. D., Burr, L. A., Smith, H. B., Hunt, A., Dadgostar, D., Dalglish, L., Smith, S., Attree, E., Jell, G., Martyn, J., Bos, N., \& Werner-Seidler, A. (2018). Turning gold into lead: Dampening appraisals reduce happiness and pleasantness and increase sadness during anticipation and recall of pleasant activities in the laboratory. Behaviour Research and Therapy, 107, 19-33. https://doi.org/10.1016/j.brat.2018.05.003

Dunn, B. D., German, R. E., Khazanov, G., Xu, C., Hollon, S. D., \& DeRubeis, R. J. (2019). Changes in positive and negative affect during pharmacological treatment and cognitive therapy for major depressive disorder: A secondary analysis of two randomized controlled trials. Clinical Psychological Science, 216770261986342. https://doi.org/10.1177/2167702619863427

Eisner, L. R., Johnson, S. L., \& Carver, C. S. (2009). Positive affect regulation in anxiety disorders. Journal of Anxiety Disorders, 23(5), 645-649. https://doi.org/10.1016/j.janxdis.2009.02.001

Feldman, G. C., Joormann, J., \& Johnson, S. L. (2008). Responses to positive affect: A self-report measure of rumination and dampening. Cognitive Therapy and Research, 32(4), 507. http://dx.doi.org/10.1007/s10608-006-9083-0

Fisher, R. J. (1993). Social desirability bias and the validity of indirect questioning. Journal of Consumer Research, 20(2), 303-315. https://doi.org/10.1086/209351

Garnefski, N., \& Kraaij, V. (2007). The cognitive emotion regulation questionnaire. European Journal of Psychological Assessment, 23(3), 141-149. https://doi.org/10.1027/1015-5759.23.3.141

Gaunt, R., \& Scott, J. (2014). Parents' involvement in childcare: Do parental and work identities matter? Psychology of Women Quarterly, 38(4), 475-489. https://doi.org/10.1177/0361684314533484

Gentzler, A. L., Morey, J. N., Palmer, C. A., \& Yi, C. Y. (2013). Young adolescents' responses to positive events: Associations with positive affect and adjustment. The Journal of Early Adolescence, 33(5), 663683. https://doi.org/10.1177/0272431612462629 
Goodin, B. R., McGuire, L. M., Stapleton, L. M., Quinn, N. B., Fabian, L. A., Haythornthwaite, J. A., \& Edwards, R. R. (2009). Pain catastrophizing mediates the relation between self-reported strenuous exercise involvement and pain ratings: The moderating role of anxiety sensitivity. Psychosomatic Medicine, 71(9), 1018-1025. https://doi.org/10.1097/PSY.0b013e3181bc62

Gross, J. J. (1998). Antecedent-and response-focused emotion regulation: Divergent consequences for experience, expression, and physiology. Journal of Personality and Social Psychology, 74(1), 224-237. http://dx.doi.org/10.1037/0022-3514.74.1.224

Gross, J. J., \& John, O. P. (2003). Individual differences in two emotion regulation processes: Implications for affect, relationships, and well-being. Journal of Personality and Social Psychology, 85(2), 348-362. https://doi.org/10.1037/0022-3514.85.2.348

Gross, J. J., \& Muñoz, R. F. (1995). Emotion regulation and mental health. Clinical Psychology: Science and Practice, 2(2), 151-164. http://dx.doi.org/10.1111/j.1468-2850.1995.tb00036.x

Gu, J., Strauss, C., Bond, R., \& Cavanagh, K. (2015). How do mindfulness-based cognitive therapy and mindfulness-based stress reduction improve mental health and wellbeing? A systematic review and meta-analysis of mediation studies. Clinical Psychology Review, 37, 1-12. https://doi.org/10.1016/j.cpr.2015.01.006

Hayes, A. F. (2018). Introduction to mediation, moderation, and conditional process analysis: A regressionbased approach (2nd ed.). The Guilford Press.

Hou, W. K., Lau, K. M., Ng, S. M., Cheng, A. C. K., Shum, T. C. Y., Cheng, S. T., \& Cheung, H. Y. S. (2016). Savoring moderates the association between cancer-specific physical symptoms and depressive symptoms. Psycho-Oncology, 26(2), 231-238. https://doi.org/10.1002/pon.4114

Hurley, D. B., \& Kwon, P. (2013). Savoring helps most when you have little: Interaction between savoring the moment and uplifts on positive affect and satisfaction with life. Journal of Happiness Studies, 14(4), 1261-1271. http://dx.doi.org/10.1007/s10902-012-9377-8

Joormann, J., \& Gotlib, I. H. (2010). Emotion regulation in depression: Relation to cognitive inhibition. Cognition and Emotion, 24(2), 281-298. http://dx.doi.org/10.1080/02699930903407948

Joormann, J., \& Vanderlind, W. M. (2014). Emotion regulation in depression: The role of biased cognition and reduced cognitive control. Clinical Psychological Science, 2(4), 402-421. https://doi.org/10.1177/2167702614536163

Jose, P. E., Lim, B. T., \& Bryant, F. B. (2012). Does savoring increase happiness? A daily diary study. The Journal of Positive Psychology, 7(3), 176-187. https://doi.org/10.1080/17439760.2012.671345

Kawakubo, A., Bryant, F. B., Miyakawa, E., \& Oguchi, T. (2019). Development and validation of the Japanese version of the Savoring Beliefs Inventory (SBI-J). Journal of Positive Psychology and Wellbeing, 3, 119-136.

Kendall, A. D., Zinbarg, R. E., Bobova, L., Mineka, S., Revelle, W., Prenoveau, J. M., \& Craske, M. G. (2015). Measuring positive emotion with the mood and anxiety symptom questionnaire: Psychometric properties of the anhedonic depression scale. Assessment, 23(1), 86-95. https://doi.org/10.1177/1073191115569528

Khazanov, G. K., \& Ruscio, A. M. (2016). Is low positive emotionality a specific risk factor for depression? A meta-analysis of longitudinal studies. Psychological Bulletin, 142(9), 991-1015. https://doi.org/10.1037/bul0000059

Koval, P., Kuppens, P., Allen, N. B., \& Sheeber, L. (2012). Getting stuck in depression: The roles of rumination and emotional inertia. Cognition $\mathcal{E}$ Emotion, 26(8), 1412-1427. https://doi.org/10.1080/02699931.2012.667392

Koval, P., Pe, M. L., Meers, K., \& Kuppens, P. (2013). Affect dynamics in relation to depressive symptoms: Variable, unstable or inert? Emotion, 13(6), 1132-1141. https://doi.org/10.1037/a0033579

Kroenke, K., \& Spitzer, R. L. (2002). The PHQ-9: A new depression diagnostic and severity measure. Psychiatric Annals, 32(9), 509-515. https://doi.org/10.3928/0048-5713-20020901-06

Kroenke, K., Spitzer, R. L., \& Williams, J. (2001). The PHQ-9: Validity of a brief depression severity measure. Journal of General Internal Medicine, 16(9), 606-613. https://doi.org/10.1046/j.15251497.2001.016009606.x

Kung, F. Y. H., Eibach, R. P., \& Grossmann, I. (2016). Culture, fixed-world beliefs, relationships, and 
perceptions of identity change. Social Psychological and Personality Science, (7), 631-639. https://doi.org/10.1177/1948550616652208

Kuppens, P., Allen, N. B., \& Sheeber, L. (2010). Emotional inertia and psychological maladjustment. Psychological Science, 21, 984 -991. doi: 10.1177/0956797610372634

Kurtz, J. L. (2015). Seeing through new eyes: An experimental investigation of the benefits of photography. Journal of Basic \& Applied Sciences, 11, 354-358. http://dx.doi.org/10.6000/1927-5129.2015.11.51

Lee, J. S., Ahn, Y. S., Jeong, K. S., Chae, J. H., \& Choi, K. S. (2014). Resilience buffers the impact of traumatic events on the development of PTSD symptoms in firefighters. Journal of Affective Disorders, 162, 128133. https://doi.org/10.1016/j.jad.2014.02.031

Levin, R. L., Heller, W., Mohanty, A., Herrington, J. D., \& Miller, G. A. (2007). Cognitive deficits in depression and functional specificity of regional brain activity. Cognitive Therapy and Research, 31(2), 211-233. https://doi.org/10.1007/s10608-007-9128-z

Lewinsohn, P. M., \& Graf, M. (1973). Pleasant activities and depression. Journal of Consulting and Clinical Psychology, 41(2), 261-268. http://dx.doi.org/10.1037/h0035142

Li, N. P., Patel, L., Balliet, D., Tov, W., \& Scollon, C. N. (2011). The incompatibility of materialism and the desire for children: Psychological insights into the fertility discrepancy among modern countries. Social Indicators Research, 101(3), 391-404. https://doi.org/10.1007/s11205-010-9665-9

Lucas, R. E. (2007). Adaptation and the set-point model of subjective well-being: Does happiness change after major life events? Current Directions in Psychological Science, 16(2), 75-79. https://doi.org/10.1111/j.1467-8721.2007.00479.x

MacLeod, A. K., \& Byrne, A. (1996). Anxiety, depression, and the anticipation of future positive and negative experiences. Journal of Abnormal Psychology, 105(2), 286-289. http://dx.doi.org/10.1037/0021843X.105.2.286

Maxwell, S. E., Cole, D. A., \& Mitchell, M. A. (2011). Bias in cross-sectional analyses of longitudinal mediation: Partial and complete mediation under an autoregressive model. Multivariate Behavioral Research, 46(5), 816-841. https://doi.org/10.1080/00273171.2011.606716

McMakin, D. L., Siegle, G. J., \& Shirk, S. R. (2011). Positive affect stimulation and sustainment (PASS) module for depressed mood: A preliminary investigation of treatment-related effects. Cognitive Therapy and Research, 35(3), 217-226. https://doi.org/10.1007/s10608-010-9311-5

Meyer, T. J., Miller, M. L., Metzger, R. L., \& Borkovec, T. D. (1990). Development and validation of the penn state worry questionnaire. Behaviour Research and Therapy, 28(6), 487-495. http://dx.doi.org/10.1016/0005-7967(90)90135-6

Mineka, S., Watson, D., \& Clark, L. A. (1998). Comorbidity of anxiety and unipolar mood disorders. Annual Review of Psychology, 49(1), 377-412. http://dx.doi.org/10.1146/annurev.psych.49.1.377

Needles, D. J., \& Abramson, L. Y. (1990). Positive life events, attributional style, and hopefulness: Testing a model of recovery from depression. Journal of Abnormal Psychology, 99(2), 156-165. http://dx.doi.org/10.1037/0021-843X.99.2.156

Nelis, S., Holmes, E. A., \& Raes, F. (2015). Response styles to positive affect and depression: Concurrent and prospective associations in a community sample. Cognitive Therapy and Research, 39(4), 480-491. https://doi.org/10.1007/s10608-015-9671-y

Nitschke, J. B., Heller, W., Imig, J. C., McDonald, R. P., \& Miller, G. A. (2001). Distinguishing dimensions of anxiety and depression. Cognitive Therapy and Research, 25(1), 1-22. https://doi.org/10.1023/A:1026485530405

Nolen-Hoeksema, S., Morrow, J., \& Fredrickson, B. L. (1993). Response styles and the duration of episodes of depressed mood. Journal of Abnormal Psychology, 102(1), 20-28. https://doi.org/10.1037//0021843X.102.1.20

Osborne, D., Huo, Y. J., \& Smith, H. J. (2015). Organizational respect dampens the impact of group-based relative deprivation on willingness to protest pay cuts. British Journal of Social Psychology, 54(1), 159175. https://doi.org/10.1111/bjso.12069

Pollack, J. M., Vanepps, E. M., \& Hayes, A. F. (2012). The moderating role of social ties on entrepreneurs' depressed affect and withdrawal intentions in response to economic stress. Journal of Organizational Behavior, 33(6), 789-810. https://doi.org/10.1002/job.1794 
Price, J. L., \& Drevets, W. C. (2010). Neurocircuitry of mood disorders. Neuropsychopharmacology, 35(1), $192-$ 216. https://doi.org/10.1038/npp.2009.104

Quoidbach, J., Berry, E. V., Hansenne, M., \& Mikolajczak, M. (2010). Positive emotion regulation and wellbeing: Comparing the impact of eight savoring and dampening strategies. Personality and Individual Differences, 49(5), 368-373. https://doi.org/10.1016/j.paid.2010.03.048

Quoidbach, J., Wood, A., \& Hansenne, M. (2009). Back to the future: The effect of daily practice of mental time travel into the future on happiness and anxiety. Journal of Positive Psychology, 4, 349-355. http://dx.doi.org/10.1080/17439760902992365

R Core Team (2019). R: A language and environment for statistical computing. R Foundation for Statistical Computing. https://www.R-project.org/.

Raes, F., Smets, J., Nelis, S., \& Schoofs, H. (2012). Dampening of positive affect prospectively predicts depressive symptoms in non-clinical samples. Cognition $\mathcal{E}$ Emotion, 26(1), 75-82. https://doi.org/10.1080/02699931.2011.555474

Ramsey, M. A., \& Gentzler, A. L. (2014). Age differences in subjective well-being across adulthood: The roles of savoring and future time perspective. The International Journal of Aging and Human Development, 78(1), 3-22. https://doi.org/10.2190/AG.78.1.b

Rees, T., \& Freeman, P. (2009). Social support moderates the relationship between stressors and task performance through self-efficacy. Journal of Social and Clinical Psychology, 28(2), 244-263. https://doi.org/10.1521/jscp.2009.28.2.244

Rosseel, Y. (2012). lavaan: An R package for structural equation modeling. Journal of Statistical Software, 48(2), 1-36. http://www.jstatsoft.org/v48/i02/.

Seligman, M. E. P., Steen, T. A., Park, N., \& Peterson, C. (2005). Positive psychology progress: Empirical validation of interventions. American Psychologist, 60(5), 410-421. https://doi.org/10.1037/0003066X.60.5.410

Sharp, P. B., Miller, G. A., \& Heller, W. (2015). Transdiagnostic dimensions of anxiety: Neural mechanisms, executive functions, and new directions. International Journal of Psychophysiology, 98(2), 365-377. https://doi.org/10.1016/j.ijpsycho.2015.07.001

Silton, R. L., Kahrilas, I. J., Skymba, H. V., Smith, J., Bryant, F. B., \& Heller, W. (2020). Regulating positive emotions: Implications for promoting well-being in individuals with depression. Emotion, 20(1), 9397. https://doi.org/10.1037/emo0000675

Smith, J. L., \& Bryant, F. B. (2017). Savoring and well-being: Mapping the cognitive-emotional terrain of the happy mind. In M. D. Robinson \& M. Eid (Eds.), The Happy Mind: Cognitive Contributions to WellBeing (pp. 139-156). Springer.

Smith, J. L., \& Hanni, A. A. (2019). Effects of a savoring intervention on resilience and well-being of older adults. Journal of Applied Gerontology, 38, 137-152. https://doi.org/10.1177/0733464817693375

Smith, J. L., Harrison, P. R., Kurtz, J. L., \& Bryant, F. B. (2014). Nurturing the capacity to savor: Interventions to enhance the enjoyment of positive experiences. In The Wiley Blackwell Handbook of Positive Psychological Interventions (pp. 42-65). John Wiley \& Sons.

Smith, J. L., \& Hollinger-Smith, L. (2015). Savoring, resilience, and psychological well-being in older adults. Aging \& Mental Health, 19(3), 192-200. http://dx.doi.org/10.1080/13607863.2014.986647

Smith, N. A., Martinez, L. R., \& Sabat, I. E. (2016). Weight and gender in service jobs: The importance of warmth in predicting customer satisfaction. Cornell Hospitality Quarterly, 57(3), 314-328. https://doi.org/10.1177/1938965515622564

Stöber, J., \& Joormann, J. (2001). Worry, procrastination, and perfectionism: Differentiating amount of worry, pathological worry, anxiety, and depression. Cognitive Therapy and Research, 25(1), 49-60. http://dx.doi.org/10.1023/A:1026474715384

Suh, E., Diener, E., \& Fujita, F. (1996). Events and subjective well-being: Only recent events matter. Journal of Personality and Social Psychology, 70(5), 1091. http://dx.doi.org/10.1037/0022-3514.70.5.1091

Thai, N., Taber-Thomas, B. C., \& Pérez-Edgar, K. E. (2016). Neural correlates of attention biases, behavioral inhibition, and social anxiety in children: An ERP study. Developmental Cognitive Neuroscience, 19, 200 210. https://doi.org/10.1016/j.dcn.2016.03.008

Thomas, K. K., \& Bowker, J. C. (2015). Rejection sensitivity and adjustment during adolescence: Do 
friendship self-silencing and parent support matter? Journal of Child and Family Studies, 24(3), 608-616. https://doi.org/10.1007/s10826-013-9871-6

Thompson, R. J., Mata, J., Jaeggi, S. M., Buschkuehl, M., Jonides, J., \& Gotlib, I. H. (2012). The everyday emotional experience of adults with major depressive disorder: Examining emotional instability, inertia, and reactivity. Journal of Abnormal Psychology, 121, 819-829.doi:10.1037/a0027978

Torres, L., \& Taknint, J. T. (2015). Ethnic microaggressions, traumatic stress symptoms, and Latino depression: A moderated mediational model. Journal of Counseling Psychology, 62(3), 393-401. https://doi.org/10.1037/cou0000077

Tsenkova, V. K., Dienberg Love, G., Singer, B. H., \& Ryff, C. D. (2008). Coping and positive affect predict longitudinal change in glycosylated hemoglobin. Health Psychology, 27(2S), S163. https://doi.org/10.1037/0278-6133.27.2

Warr, P. B., Barter, J., \& Brownbridge, G. (1983). On the independence of positive and negative affect. Journal of Personality and Social Psychology, 44(3), 644-651. http://dx.doi.org/10.1037/0022-3514.44.3.644

Watson, D. (2009). Positive affectivity. In C. R. Snyder \& S. J. Lopez (2nd ed.), Oxford Handbook of Positive Psychology (pp. 106-119). Oxford University Press.

Watson, D., \& Clark, L. A. (1984). Negative affectivity: The disposition to experience aversive emotional states. Psychological Bulletin, 96, 465-490. http://dx.doi.org/10.1037/0033-2909.96.3.465

Watson, D., Clark, L. A., \& Carey, G. (1988). Positive and negative affectivity and their relation to anxiety and depressive disorders. Journal of Abnormal Psychology, 97(3), 346. http://dx.doi.org/10.1037/0021843X.97.3.346

Watson, D., Clark, L. A., Weber, K., Assenheimer, J. S., Strauss, M. E., \& McCormick, R. A. (1995). Testing a tripartite model: II. Exploring the symptom structure of anxiety and depression in student, adult, and patient samples. Journal of Abnormal Psychology, 104(1), 15-25. http://dx.doi.org/10.1037/0021843X.104.1.15

Watson, D., Weber, K., Assenheimer, J. S., Clark, L. A., Strauss, M. E., \& McCormick, R. A. (1995). Testing a tripartite model: I. Evaluating the convergent and discriminant validity of anxiety and depression symptom scales. Journal of Abnormal Psychology, 104(1), 3-14. http://dx.doi.org/10.1037/0021843X.104.1.3

Webb, J. B., Fiery, M. F., \& Jafari, N. (2016). "You better not leave me shaming!": Conditional indirect effect analyses of anti-fat attitudes, body shame, and fat talk as a function of self-compassion in college women. Body Image, 18, 5-13. https://doi.org/10.1016/j.bodyim.2016.04.009

Werner-Seidler, A., Banks, R., Dunn, B. D., \& Moulds, M. L. (2013). An investigation of the relationship between positive affect regulation and depression. Behaviour Research and Therapy, 51(1), 46-56. https://doi.org/10.1016/j.brat.2012.11.001

Zhang, Z. (2014). Monte Carlo based statistical power analysis for mediation models: Methods and software. Behavior Research Methods, 46(4), 1184-1198. https://doi.org/10.3758/s13428-013-0424-0 